This is a postprint version of the following published document:

L. Bolzoni, E.M. Ruiz-Navas, E. Gordo (2014). Investigation of the factors influencing the tensile behaviour of PM Ti-3Al-2.5V alloy. In Materials Science and Engineering A, Volume: 609, July, Pages: 266-272.

http://dx.doi.org/10.1016/j.msea.2014.05.017

(C) 2014 Elsevier

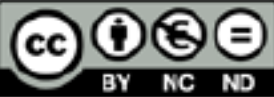

This work is licensed under a Creative Commons Attribution-NonCommercialNoDerivatives 4.0 International License. 


\title{
Investigation of the factors influencing the tensile behaviour of PM Ti-3Al-2.5V alloy
}

\author{
L. Bolzoni , E.M. Ruiz-Navas, E. Gordo \\ Departamento de Ciencia e Ingeniería de Materiales e Ingeniería Química, Universidad Carlos III de Madrid, Avda. de la Universidad, 30,28911 Leganés, \\ Madrid, Spain
}

\begin{abstract}
Titanium, a relatively new engineering metal, has been employed principally in high demanding industries due to its high final cost and it is well known for its biocompatibility. Powder metallurgy (PM) techniques could offer the possibility to reduce the production cost without paying it in terms of mechanical properties, thanks to their intrinsic advantages. In this study the Ti-3Al-2.5V titanium alloy was produced considering two powder production routes and sintered under different temperatures in order to address their feasibility as alternative to the wrought alloy. The results indicate that PM Ti-3Al-2.5V alloys studied have comparable mechanical behaviour as their counterpart obtained by conven-tional metallurgy and, therefore, are potential candidates to fabricate cheaper titanium products for structural applications as well as biomedical devices.
\end{abstract}

Keyword: Titanium alloys, Ti-3Al-2.5V, Powder metallurgy, Tensile properties, Dynamic Young modulus

\section{Introduction}

Titanium and its alloys have been discovered, developed and employed only in the last century $[1,2]$ and, thus, they are relatively new engineering materials compared to other metals like steel or aluminium. The extraction and production costs of titanium still remain significantly higher with respect to its competitors due to its electronic structure [3] and, therefore, to the high affinity of this metal for atmospheric elements such as oxygen, nitrogen and hydrogen, as well as for other interstitials like carbon. Moreover, titanium has poor machinability due to its low thermal conductivity. These aspects have confined the application of titanium and titanium alloys to high demanding and high performing industries, such as aeronautical, medical and chemical, where the final cost is not the most important factor but the safety or the combination of properties provided [4]. Albeit the nearalpha Ti-3Al-2.5V alloy was originally developed for aircraft parts and components, it is nowadays also employed in the fabrication of sport equipments as well as medical and dental implants [5]. This is because the Ti-3Al-2.5V alloy has intermediate properties (mechanical strength and corrosion resistance) between elemental

Corresponding author: Tel.: +3491624 9482; fax: +34916249430. E-mail address: bolzoni.leandro@gmail.com (L. Bolzoni). titanium and the Ti-6Al-4V alloy and it is cheaper due to the lower amount of alloying elements [6].

Powder metallurgy (PM) techniques offer well-established advantages, like a more efficient material utilisation, which would permit costs reduction, especially when processing expensive and difficult-to-produce materials. In the case of titanium and its alloys this advantage is combined with the fact that the reaction between titanium and the fabrication tools is prevented or limited because sintering is carried out in the solid state. This aspect is of particular importance for titanium because the metal in the molten state strongly reacts with the ceramic moulds forming a brittle superficial layer, known as alpha-case [7], which has to be removed either mechanically or chemically.

Even though the production of titanium, mainly focusing on the Ti-6Al-4V alloy, by means of PM methods was considered in the 1980s [8-12], the mechanical properties were affected by the presence of chlorines, such as $\mathrm{NaCl}$ or $\mathrm{MgCl}_{2}$, left from Kroll's extraction process in the starting sponge powders [13]. It is, thus, worth studying the fabrication of titanium components, because nowadays titanium powder obtained by means of comminution process is available in the market, specifically the so-called hydride-dehydride (HDH) method, which permits one to avoid the presence of chorines [14]. Moreover, to the best of our knowledge no studies were performed on the performances of the Ti-3Al-2.5V alloy. Therefore, the aim of this work is to investigate the feasibility of the production of the Ti-3Al-2.5V 
alloy as an alternative route to obtain cheaper biomedical devices with properties comparable to those of the wrought Ti-3Al-2.5V and/or Ti-6Al-4V alloys. In particular, the alloy is produced considering two alternative ways to introduce the alloying elements to the starting $\mathrm{HDH}$ elemental titanium powder and consolidated by cold uniaxial pressing. An in-depth study of the influence of the different aspects (i.e. microstructural features, densification, relative density and interstitials content) affecting the performances of the materials produced is carried out.

\section{Experimental procedure}

\subsection{Raw materials and $T i-3 A l-2.5 \mathrm{~V}$ powders}

The raw materials acquired for the production of the Ti-3Al$2.5 \mathrm{~V}$ powders were: $\mathrm{HDH}$ elemental titanium powder and $\mathrm{V}: \mathrm{Al}$ master alloy (both supplied by GfE Gesellschaft für Elektrometallurgie $\mathrm{mbH}$ ) as well as an $\mathrm{HDH}$ Ti-6Al-4V powder (prealloyed) procured from Se-Jong Materials. Thanks to this set of starting powders, the Ti-3Al-2.5V alloy was produced considering the socalled master alloy addition alternative of the blending elemental approach. Specifically, on the one hand, the elemental titanium powder was mixed with the V:Al master alloy whilst on the other hand the elemental titanium powder was alloyed with the right amount of Ti-6Al-4V powder. In order to differentiate the two Ti$3 \mathrm{Al}-2.5 \mathrm{~V}$ powders, they were labelled as a function of the nature of the alloying elements as Ti-3Al-2.5V-MA and Ti-3Al-2.5V-PA, respectively. The preparation of the powders was done by conventional blending by means of a Turbula mixer during $30 \mathrm{~min}$ [15]. The characteristics of the Ti-3Al-2.5V-MA and Ti-3Al-2.5VPA powders quantified were morphology (SEM analysis), particle size distribution (Malvern Instrument laser beam MasterSizer analyser) and interstitials contents (amounts of oxygen and nitrogen measured with a LECO TC-500 analyser as per ASTM: E1409).

\subsection{Shaping and sintering of the Ti-3Al-2.5V powders}

Ti-3Al-2.5V-MA and Ti-3Al-2.5V-PA powders were shaped into dogbone tensile specimens (ASTM: B925) by means of a hydraulic uniaxial press and a floating die. The walls of the floating die were lubricated with zinc stearate. No lubricant was intentionally added to the starting powders in order to prevent or limit as much as possible their contamination. The pressure applied to consolidate the powder was set to $700 \mathrm{MPa}$, a common value employed in the PM industry [16], because this pressure permits obtaining high green density without the delamination of the samples. For sintering, the green specimens were laid into zirconia beads placed inside an alumina tray. The specimens were subsequently sintered by means of a high-vacuum tubular furnace. Heating and cooling of the samples were done at $5{ }^{\circ} \mathrm{C} / \mathrm{min}$ and a minimum vacuum level of $10^{-5}$ mbar was guaranteed. The sintering temperature range considered was between $1250{ }^{\circ} \mathrm{C}$ and $1350{ }^{\circ} \mathrm{C}$ whilst the sintering time was kept constant at $120 \mathrm{~min}$. These parameters were selected on the base of a previous study where it was demonstrated that the increment of the sintering time is not as effective as the increment of the processing temperature to reach high relative density values [17]. It is worth mentioning that due to the layout of the furnace, sintering was carried out discontinuously (by-batches) but a minimum of three samples per material/condition were considered each time.

\subsection{Characterisation of the sintered Ti-3Al-2.5V alloys}

The sintered samples were prepared for metallography using silicon-carbide papers with different granulometry for grinding and silica gel for polishing. The phases that compose the microstructure were revealed by means of Kroll etching, a mixture of hydrofluoric and nitric acids plus distilled water, as well as identified by XRD analysis. Microstructural analysis was done using an Olympus GX-71 optical microscope. The thickness of the sintered Ti-3Al-2.5V-MA and Ti-3Al-2.5V-PA samples was measured by means of a micrometer and its variation was monitored to study the effect of the sintering step on the final shape of the components. The so-called densification parameter $(\Psi)$ was calculated on the base of the ratio between the difference of the density of the sintered specimens $\left(\rho_{\text {sint }}\right)$ with the green density $\left(\rho_{\text {green }}\right)$ and the nominal density $\left(\rho_{n}\right)$ with the green density to quantify the phenomenon governing the sintering step. More in detail, $\rho_{\text {sint }}$ : value of the density of the sintered samples obtained by water displacement measurements $\left[\mathrm{g} / \mathrm{cm}^{3}\right], \rho_{\text {green }}$ : ratio between the weight and the volume of green samples $[\mathrm{g} /$ $\left.\mathrm{cm}^{3}\right], \rho_{n}$ : nominal value of the density of the wrought Ti-3Al-2.5V alloy $\left[4.48 \mathrm{~g} / \mathrm{cm}^{3}\right]$ [18]. Due to their great effect on the final mechanical properties of titanium and its alloys, oxygen and nitrogen contents were also monitored and the percentage present in the sintered specimens was determined as specified in Section 2.1 (LECO TC-500 as per ASTM: E1409). Concerning the mechanical performances, hardness and tensile tests were considered. In particular, HV30 Vickers hardness measurements were performed by means of a Wilson Wolpert DIGITESTOR-930 universal tester while a MicroTest universal machine was used for tensile tests with a crosshead speed of $1 \mathrm{~mm} / \mathrm{min}$ (ASTM: E8). The universal tensile machine was equipped with a load cell of $50 \mathrm{KN}$ and a DD1 type extensometer (Hottinger Baldwin Messtechnik). Fractography of the fracture surface of tensile specimens was carried out on a Philips XL30 SEM. This same SEM in combination with an EDS detector was also employed to verify the homogeneous distribution and the alloying elements. The dynamic Young modulus was considered in order to prevent possible errors that the offset method can introduce. For that, an ultrasonic transducer (Grindosonic) having a frequency range in between $20 \mathrm{~Hz}$ and $100 \mathrm{KHz}$ and an accuracy better than $0.005 \%$ was employed for determining the speed of sound $(v)$. The dynamic Young modulus of the sintered tensile samples was asserted considering the relation between this parameter with the density and the speed of sound $v=\sqrt{E_{d} / \rho_{r}}$.

\section{Results}

\subsection{Ti-3Al-2.5V-MA and Ti-3Al-2.5V-PA powders characterisation}

Fig. 1 reports the SEM images taken to check the morphology of the Ti-3Al-2.5V-MA and Ti-3Al-2.5V-PA powders.

From Fig. 1 it can be seen that both powders are characterised by an irregular morphology due to the comminution process (i.e. $\mathrm{HDH}$ ) employed to fabricate them. The irregular morphology is a paramount requirement for the processing of the powders by means of the conventional pressing and sintering route, especially when it comes to their shaping. Ti-3Al-2.5V-MA and Ti-3Al-2.5VPA powders are characterised by a very similar particle size distribution. Precisely, the Ti-3Al-2.5V-PA powder $\left(D_{10}=16.25 \mu \mathrm{m}\right.$ and $D_{90}=78.63 \mu \mathrm{m}$ ) has slightly finer particles size than the Ti-3Al-2.5V-PA powder $\left(D_{10}=17.22 \mu \mathrm{m}\right.$ and $\left.D_{90}=79.65 \mu \mathrm{m}\right)$. The contents of oxygen and nitrogen for the two powders are $\mathrm{O}=0.34 \mathrm{wt} \%$ and $\mathrm{N}=0.012 \mathrm{wt} \%(\mathrm{Ti}-3 \mathrm{Al}-2.5 \mathrm{~V}-\mathrm{MA})$ and $\mathrm{O}=0.40 \mathrm{wt} \%$ and $\mathrm{N}=0.010 \mathrm{wt} \%$ (Ti-3Al-2.5V-PA), respectively. From these data, it can be noticed that the Ti-3Al-2.5V-PA has higher oxygen content, which related to its lower particle size. Moreover, both powders have higher oxygen content and lower nitrogen content 

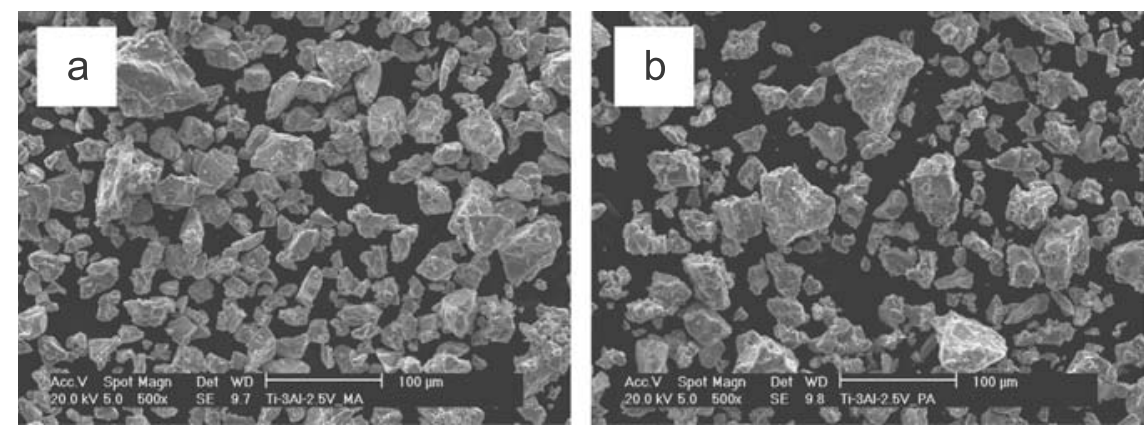

Fig. 1. SEM images of the morphology of the Ti-3Al-2.5V-MA (a) and Ti-3Al-2.5V-PA (b) powders.

with respect to the value of the wrought $\mathrm{Ti}-3 \mathrm{Al}-2.5 \mathrm{~V}$ alloy $(\mathrm{O}=0.15 \mathrm{wt} \%$ and $\mathrm{N}=0.030 \mathrm{wt} \%)[18]$.

\subsection{Ti-3Al-2.5V-MA and Ti-3Al-2.5V-PA samples characterisation}

Fig. 2 shows representative micrographs of the development of the microstructure and the evolution of the porosity of both materials.

From the analysis of the microstructure of the samples sintered at $1250{ }^{\circ} \mathrm{C}$ during $2 \mathrm{~h}$ (Fig. $2 \mathrm{a}$ and b), the microconstituents of both Ti-3Al-2.5V-MA and Ti-3Al-2.5V-PA alloys are $\alpha$ grains and $\alpha+\beta$ lamellae. Specifically, it can be noticed that the $\alpha$ phase is present in the grain boundaries of the prior $\beta$ grains as well as in between the $\beta$ needles. By the comparison of the two materials, it can be seen that the microconstituents of the Ti-3Al-2.5V-MA alloy are rather coarser than that of the Ti-3Al-2.5V-PA alloy. In particular, the $\alpha$ grains in the original grain boundaries are wider and the $\alpha+\beta$ lamellae longer and finer. This difference is mainly due to the slightly bigger particle size of the Ti-3Al-2.5V-MA powder whose particle boundaries primarily constitute the prior $\beta$ grains boundary. Another typical feature that can be clearly seen in the micrographs presented in Fig. 2 is the residual porosity which remained after sintering of the samples. The residual porosity is characterised by spherical shape, it is mostly isolated and it is found near the grain boundaries rather than inside the grain. This is because during the last stage of sintering the residual porosity tends to move and coalesce along the grain boundaries $[19,20]$ where the movement is favoured by the presence of vacancies. The Ti-3Al-2.5V-MA alloy sintered at $1250{ }^{\circ} \mathrm{C}$ is characterised by a relative uniform distribution of fine pores with some very few bigger pores whilst the Ti-3Al-2.5V-PA alloy has a wider distribution of pores sizes. Moreover, the Ti-3Al-2.5V-PA alloy has a greater volumetric percentage of residual porosity in comparison to Ti-3Al-2.5V-MA alloy, which would translate into a lower relative density. The increment of the sintering temperature to $1300{ }^{\circ} \mathrm{C}$ (Fig. 2c and d) and $1350{ }^{\circ} \mathrm{C}$ (Fig. 2e and f) leads to the coarsening of the microstructural features (i.e. $\alpha$ grains, $\alpha+\beta$ lamellae and porosity) for both Ti-3Al-2.5V-MA and Ti-3Al-2.5VPA alloys. It is interesting to notice that up to $1300{ }^{\circ} \mathrm{C}$ the great majority of the thermal energy available in the system is spent for the densification of the materials whereas afterwards a greater amount of energy is invested in grain growth.

The variation of the dimensions of the green samples experienced due to the sintering step as well as their densification is shown in Fig. 3(a) and (b), respectively.

As it can be seen in Fig. 3(a), the sintering step induces shrinkage (negative variation of the dimensions) of both Ti-3Al2.5V-MA and Ti-3Al-2.5V-PA samples. Moreover, the shrinkage slightly increases with the increment of the processing temperature for both materials although this increment is a bit higher for the Ti-3Al-2.5V-PA alloy (i.e. $0.13 \%$ versus $0.05 \%$ ). Furthermore, from Fig. 3(a) it can be seen that the Ti-3Al-2.5V-PA alloy undergoes a greater shrinkage (around $1 \%$ ) with respect to the Ti-3Al-2.5V-MA alloy. This aspect is due to the combined effect of lower particle size of the Ti-3Al-2.5V-PA powder (i.e. higher surface area and, in turn, higher sintering driving force) and the fact that the composition of the alloy is more uniform (being produced by using a prealloyed powder). Concerning the densification parameter (Fig. 3b), it can be seen that it increases continuously with the increment of the processing temperature for both materials. Furthermore, the Ti-3Al-2.5V-PA alloy experiences higher densification in comparison to the Ti-3Al-2.5V-MA alloy due to its finer particle size.

The results of the relative density as a function of the sintering temperature are shown in Fig. 4.

From the data of the relative density shown in Fig. 4, it can be seen that this property increases linearly with the increment of the sintering temperature and, consequently, the total residual porosity decreases. In particular, the relative density of the Ti-3Al2.5V-MA alloy sintered samples increases by approximately $0.5 \%$ with the increment of $50{ }^{\circ} \mathrm{C}$ of processing temperature. This continuous increment reflects the trend of both the shrinkage experienced by the samples and the densification parameter (Fig. 3), which increases linearly with the increment of the sintering temperature. In the case of the Ti-3Al-2.5V-PA alloy, the increment of the relative density is much greater when the processing temperature is increased from $1250{ }^{\circ} \mathrm{C}$ to $1300{ }^{\circ} \mathrm{C}$ $\left(\Delta \rho_{r}=1.1 \%\right)$ and then from $1300{ }^{\circ} \mathrm{C}$ to $1350{ }^{\circ} \mathrm{C}\left(\Delta \rho_{r}=0.1 \%\right)$.

The results of the chemical analysis, contents of oxygen and nitrogen, carried out on sintered samples are presented in Table 1.

Analysing the content of oxygen as determined by inert gas fusion technique in the sintered samples (Table 1), it can be noticed that the two materials have different behaviour. On the one hand, the Ti-3Al-2.5V-MA alloy shows more or less a constant oxygen content $(0.35 \mathrm{wt} \%)$ with the increment of sintering temperature. On the other hand, the final amount of oxygen dissolved in the Ti-3Al-2.5V-PA alloy increases with the increment of the processing temperature. Moreover, there is also an increment with respect to the amount of oxygen measured on the starting powder and the final percentage is greater than the typical value of the wrought alloy [18]. In the case of nitrogen percentage, the trend found is the same as for oxygen; therefore, nitrogen is fairly constant for Ti-3Al-2.5V-MA alloy and slightly increases for Ti$3 \mathrm{Al}-2.5 \mathrm{~V}-\mathrm{PA}$ alloy. Nevertheless, even in the worst of the cases the final nitrogen content is lower with respect to the value specified for the wrought Ti-3Al-2.5V alloy (i.e. $0.03 \mathrm{wt} \%$ ) [18].

The results of Vickers hardness (HV30) measured in the crosssection of Ti-3Al-2.5V-MA and Ti-3Al-2.5V-PA specimens are presented in Fig. 5.

As can be seen from the data plotted in Fig. 5, generally, the hardness of both Ti-3Al-2.5V-MA and Ti-3Al-2.5V-PA alloys increases with the increment of the sintering temperature. This behaviour is the direct consequence of the increment of the relative density or, in turn, to the reduction of the volumetric 

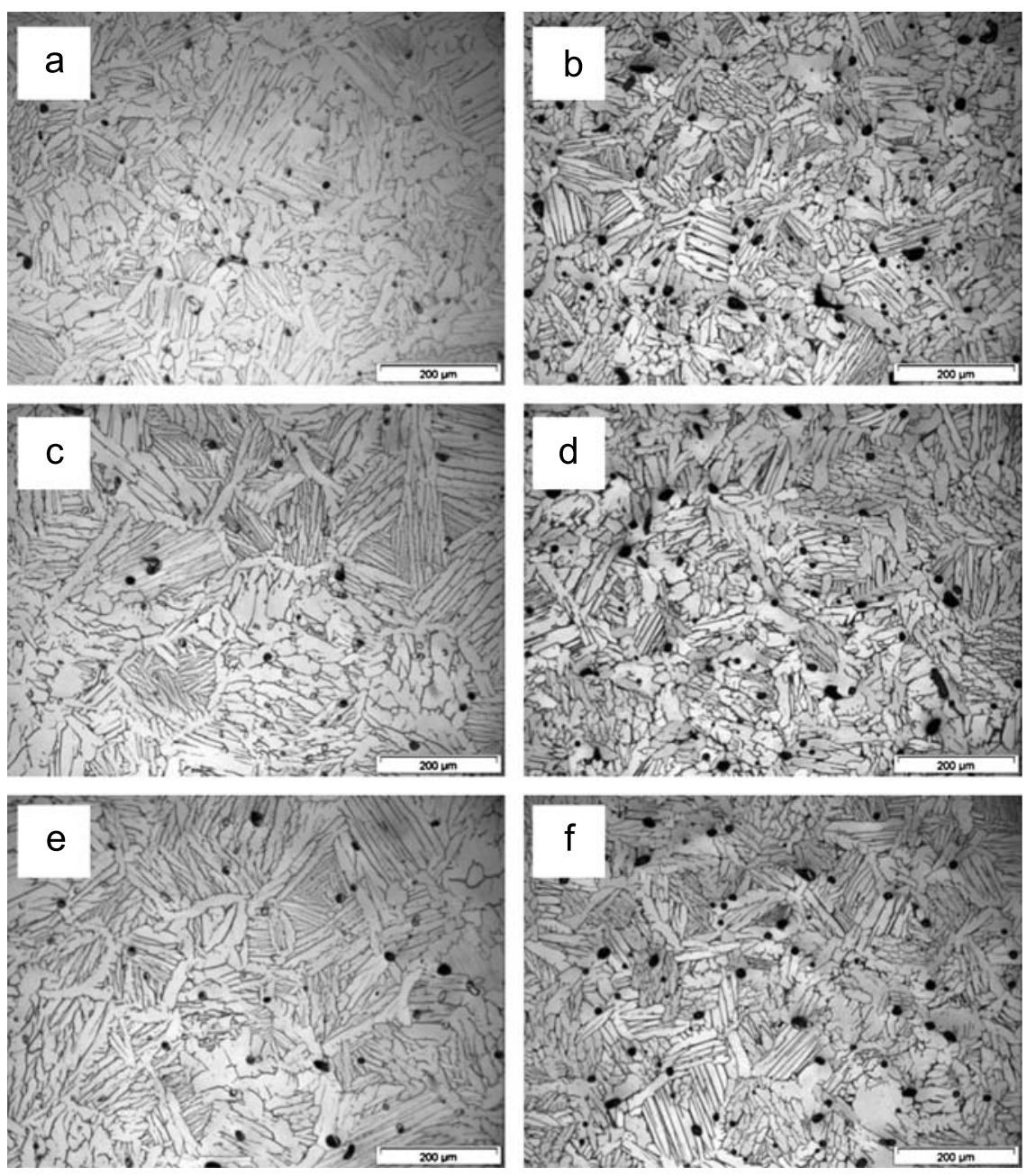

Fig. 2. Micrographs of Ti-3Al-2.5V-MA and Ti-3Al-2.5V-PA samples, respectively, sintered during $2 \mathrm{~h}$ at: (a) and (b) $1250{ }^{\circ} \mathrm{C}$, (c) and (d) $1300{ }^{\circ} \mathrm{C}$ and (e) and (f) $1350{ }^{\circ} \mathrm{C}$.

amount of residual porosity in the microstructure of the alloys and it is the expected trend for PM materials. Nevertheless, it can also be noticed that there are slight variations from a linear and continuous increment of the hardness which, in the case of dealing with titanium alloys, are dictated by the content of interstitials [21,22].

Examples of tensile stress-strain curves obtained from the tensile tests of the PM Ti-3Al-2.5V-MA and Ti-3Al-2.5V-PA alloy samples are displayed in Fig. 6.

As can be seen in Fig. 6, the shape of the tensile stress-strain curves of both the PM Ti-3Al-2.5V-MA and Ti-3Al-2.5V-PA alloys is similar because the materials undergo an elastic deformation up to approximately $700 \mathrm{MPa}$ and then start to deform plastically. From these stress-strain curves, it can be seen that there is a slight variation of the ultimate load that the materials can withstand but the biggest difference is in terms of total deformation before fracture. It is worth mentioning that all the Ti-3Al-2.5V-MA and Ti-3Al-2.5V-PA sintered samples show very similar value when subjected to an elastic deformation, as can be seen from the overlapping of the stress-strain curves. This indicated that, with the processing parameters employed to sinter the alloys, comparable Young's modulus values are obtained. Nevertheless, as indicated in the experimental procedure, the dynamic Young modulus was considered in this study to exclude any possible error due to the misalignment of the samples or sliding of the grips of the tensile machine.

The ultimate tensile strength (UTS) and strain at fracture $(\varepsilon)$ mean values for the different sintering conditions employed to process the Ti-3Al-2.5V-MA and Ti-3Al-2.5V-PA alloys are shown in Fig. 7 in comparison to the value specified for the wrought Ti-3Al-2.5V alloy.

From the analysis of the UTS data shown in Fig. 7, it can be seen that the increment of the sintering temperature leads to an increment of the strength of both materials with the exception of the Ti-3Al2.5V-PA alloy sintered at $1350^{\circ} \mathrm{C}$, which has lower strength than the samples processed at $1300{ }^{\circ} \mathrm{C}$. The increment of the strength is mainly due to the reduction of the residual porosity, which in PM products, and especially in the ones obtained by cold uniaxial pressing and sintering, acts as stress intensification sites provoking the failure of the material although there is a contribution from the interstitials dissolved because it is well known that the greater their contents, the stronger the titanium alloys become [21-23]. When considering the values of the deformation at fracture (Fig. 7), it can be seen that the ductility of both materials initially increases but then decreases when using a sintering temperature of $1350{ }^{\circ} \mathrm{C}$. Therefore, it seems that at the beginning the positive effect of the reduction of the residual porosity and of the grain growth is more powerful than the increment of the interstitial content. The presence of a greater amount of less deformable alpha phase (i.e. H.C.P.) present in the Ti-3Al-2.5V-MA alloy and the features of the residual porosity also explain the lower deformation underwent by the Ti-3Al-2.5V-MA alloy with respect to the Ti-3Al-2.5V-PA alloy despite its lower content of oxygen dissolved.

No significant differences were found on the bases of the sintering temperature during the fractographic study of the tensile test specimens by SEM. Hence, only the micrographs of the samples sintered at $1300{ }^{\circ} \mathrm{C}$ during $2 \mathrm{~h}$ are shown in Fig. 8 . 


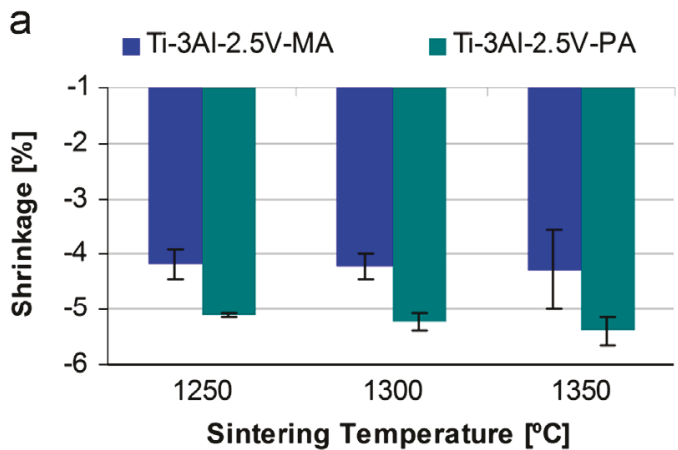

b

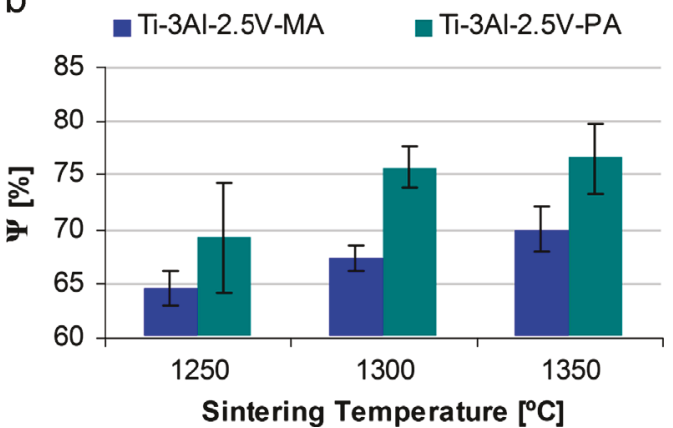

Fig. 3. Shrinkage (a) and densification (b) versus sintering temperature of Ti-3Al2.5V-MA and Ti-3Al-2.5V-PA sintered samples. (For interpretation of the references to colour in this figure, the reader is referred to the web version of this article.)

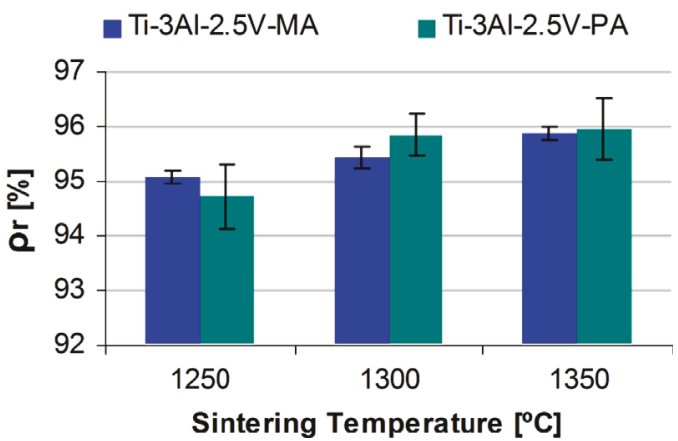

Fig. 4. Relative density versus sintering temperature of Ti-3Al-2.5V-MA and Ti-3Al-2.5V-PA sintered samples.

Table 1

Chemical analysis of Ti-3Al-2.5V-MA and Ti-3Al-2.5V-PA sintered samples.

\begin{tabular}{llll}
\hline Material & $\begin{array}{l}\text { Processing } \\
\text { conditions }\end{array}$ & \multicolumn{2}{l}{ Interstitials content [wt\%] } \\
\cline { 3 - 4 } & & Oxygen & Nitrogen \\
\hline Ti-3Al-2.5V-MA alloy & $1250{ }^{\circ} \mathrm{C}-2 \mathrm{~h}$ & $0.34 \pm 0.02$ & $0.025 \pm 0.004$ \\
& $1300{ }^{\circ} \mathrm{C}-2 \mathrm{~h}$ & $0.35 \pm 0.02$ & $0.026 \pm 0.001$ \\
& $1350^{\circ} \mathrm{C}-2 \mathrm{~h}$ & $0.34 \pm 0.03$ & $0.025 \pm 0.003$ \\
Ti-3Al-2.5V-PA alloy & $12500^{\circ} \mathrm{C}-2 \mathrm{~h}$ & $0.40 \pm 0.06$ & $0.022 \pm 0.011$ \\
& $1300{ }^{\circ} \mathrm{C}-2 \mathrm{~h}$ & $0.44 \pm 0.02$ & $0.026 \pm 0.006$ \\
& $1350{ }^{\circ} \mathrm{C}-2 \mathrm{~h}$ & $0.45 \pm 0.01$ & $0.027 \pm 0.002$ \\
Ti-3Al-2.5V & Wrought & 0.15 & 0.030 \\
\hline
\end{tabular}

From the fractographic study results (Fig. 8), it can be seen that, in general, the materials present ductile fracture due to microvoids' coalescence where the size of the dimples found in the Ti-3Al-2.5V-MA alloy seem to be larger than Ti-3Al-2.5V-PA.

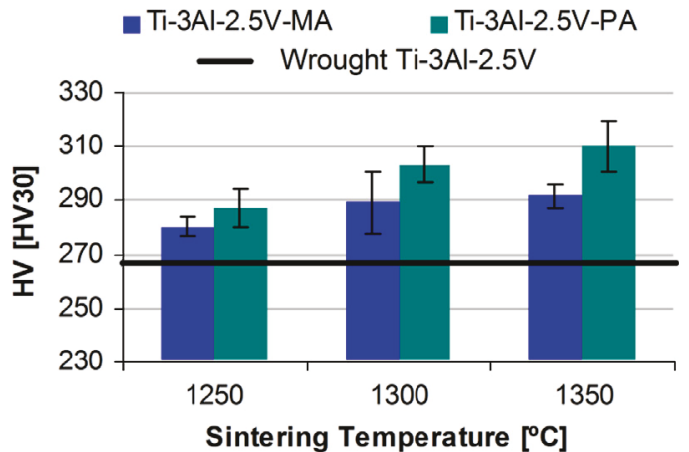

Fig. 5. Hardness versus sintering temperature of $\mathrm{Ti}-3 \mathrm{Al}-2.5 \mathrm{~V}-\mathrm{MA}$ and $\mathrm{Ti}-3 \mathrm{Al}-$ 2.5V-PA sintered samples.
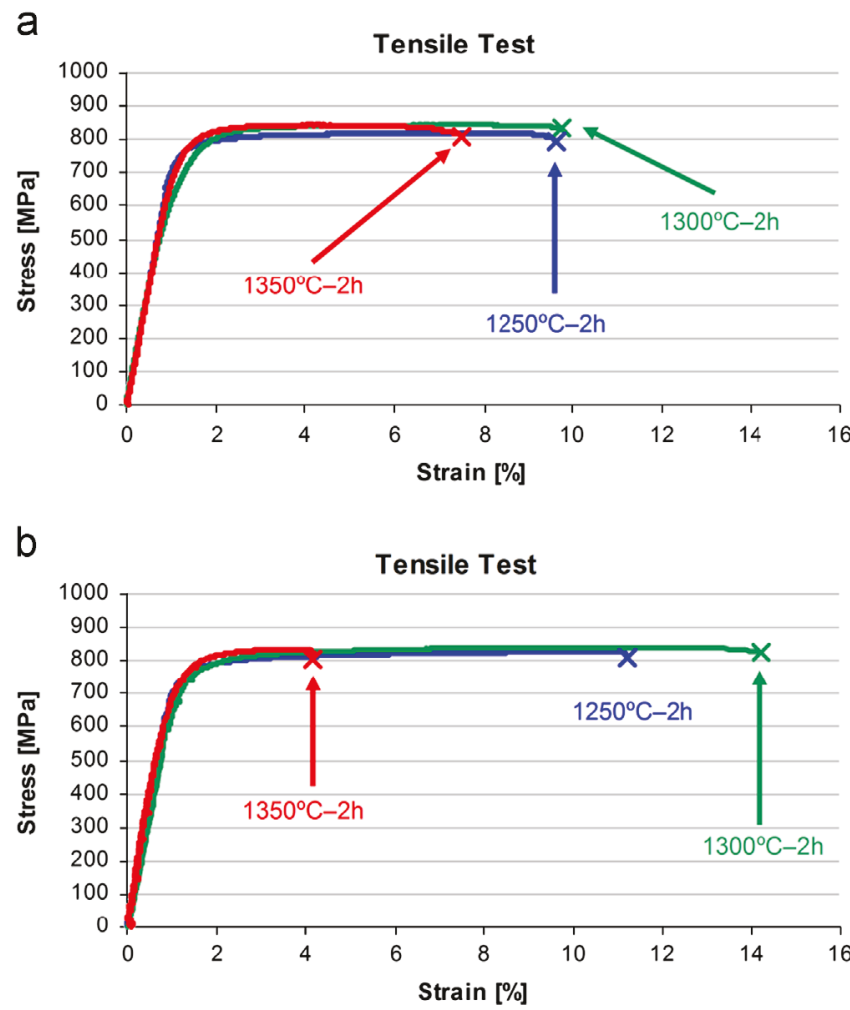

Fig. 6. Representative stress-strain behaviour of $\mathrm{Ti}-3 \mathrm{Al}-2.5 \mathrm{~V}$ sintered samples: (a) Ti-3Al-2.5V-MA and (b) Ti-3Al-2.5V-PA.

Moreover, Ti-3Al-2.5V-MA has a mixture of non-equiaxed coarse and fine dimples and some small area of cleavage, which could be due to the presence of some impurity from the master alloy. The pore-assisted fracture of Ti-3Al-2.5V-MA and Ti-3Al-2.5V-PA samples is the typical behaviour of titanium alloys obtained by the conventional ingot metallurgy [10].

The results of the dynamic Young modulus carried out on sintered Ti-3Al-2.5V-MA and Ti-3Al-2.5V-PA alloy specimens are reported in Table 2 .

From Table 2, it can be seen that the measurements of the dynamic Young modulus are very similar between them regardless of the sintering temperature which is in agreement with the results of the stress-strain curves (Fig. 6). This is because, as shown in Fig. 2, with the processing parameters employed in this study, the pore structure is mainly composed of relatively small, spherical and isolated pores. Nevertheless, the coarseness of the microstructural features combined with the distribution of the residual porosity which is characterised by slightly different 


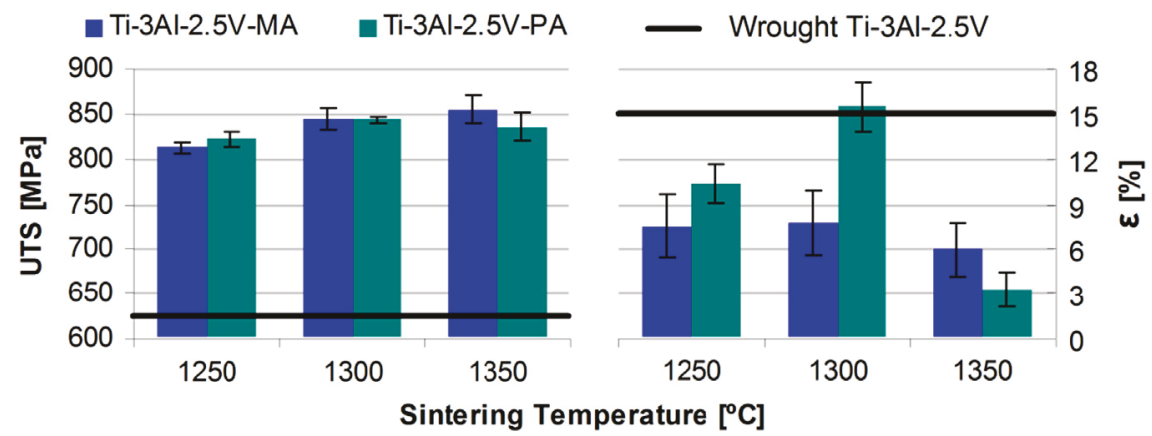

Fig. 7. Ultimate tensile strength - UTS (left) and strain at fracture - $\varepsilon$ (right) versus sintering temperature of Ti-3Al-2.5V-MA and Ti-3Al-2.5V-PA sintered samples.

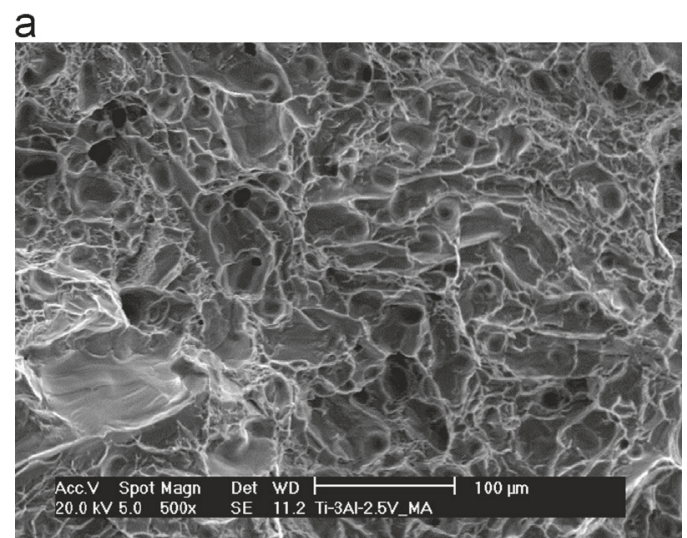

b

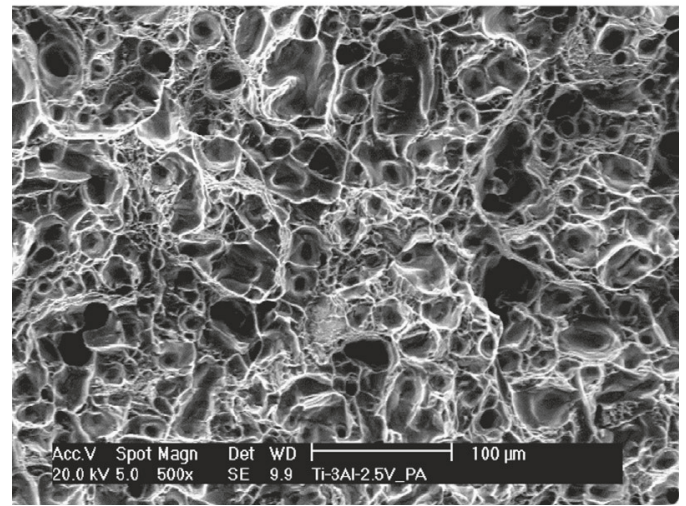

Fig. 8. Fracture surface of tensile samples sintered at $1300^{\circ} \mathrm{C}$ during $2 \mathrm{~h}$ : (a) Ti-3Al-2.5V-MA and (b) Ti-3Al-2.5V-PA.

Table 2

Dynamic Young modulus of Ti-3Al-2.5V-MA and Ti-3Al-2.5V-PA sintered samples.

\begin{tabular}{llll}
\hline Material & $\begin{array}{l}\text { Processing } \\
\text { conditions }\end{array}$ & \multicolumn{1}{l}{ Young modulus [GPa] } \\
\cline { 3 - 4 } & & & Mean value \\
\hline Ti-3Al-2.5V-MA alloy & $1250^{\circ} \mathrm{C}-2 \mathrm{~h}$ & $104 \pm 1$ & $109 \pm 6$ \\
& $1300^{\circ} \mathrm{C}-2 \mathrm{~h}$ & $106 \pm 7$ & \\
& $1350^{\circ} \mathrm{C}-2 \mathrm{~h}$ & $116 \pm 4$ & $108 \pm 6$ \\
Ti-3Al-2.5V-PA alloy & $1250^{\circ} \mathrm{C}-2 \mathrm{~h}$ & $111 \pm 2$ & \\
& $1300^{\circ} \mathrm{C}-2 \mathrm{~h}$ & $102 \pm 6$ & $112 \pm 2$ \\
Ti-3Al-2.5V & $1350^{\circ} \mathrm{C}-2 \mathrm{~h}$ & 107 & \\
\hline
\end{tabular}

features and the level of interstitials present in the machined samples in which the dynamic Young modulus measurements were performed led to local variation of the elastic modulus which is reflected in the standard deviation calculated for each processing condition.

\section{Discussion}

Independent of the processing temperature employed to sinter the Ti-3Al-2.5V-MA and Ti-3Al-2.5V-PA alloys, they are characterised by the typical lamellar microstructure of the near- $\alpha$ titanium alloys slow cooled from a temperature above their beta transus [24]. This is because the sintering temperature window chosen to process the materials in this investigation is higher than $935^{\circ} \mathrm{C}$, the nominal beta transus of the Ti-3Al-2.5V alloy [18]. It is worth mentioning that the chemical composition of the sintered materials is fully homogeneous (checked by EDS analysis), indicating that the sintering temperature selected is high enough to guarantee the complete diffusion and homogenisation of aluminium and vanadium throughout the whole material. To fully characterise the materials, XRD patterns of the sintered samples were recorded (graphs not reported for brevity) and exclusively alpha and beta titanium phases peaks were detected. By the comparison of the values of the relative density obtained for the Ti-3Al-2.5V-MA alloy and the Ti-3Al-2.5V-PA alloy (Fig. 4), although there are little differences, the comparison of the relative density of samples produced from the two types of powder (MA and PA) does not indicate a better method because the values obtained for both alloys are very similar. The relative density values shown in Fig. 4 are comparable to those obtained by other authors when processing the Ti-6Al-4V alloy using different types of powders and/or approaches [10,25-28]. The increment of the sintering temperature leads to some oxygen pick-up which is due to different aspects such as amount of oxygen adsorbed onto the surface of the particles and air trapped on the green samples. When comparing the hardness values of the two materials, it can be seen that even though they are characterised by a similar trend, the Ti-3Al-2.5V-PA alloy always show higher hardness than the Ti-3Al-2.5V-MA alloy. The higher hardness values of the Ti$3 \mathrm{Al}-2.5 \mathrm{~V}-\mathrm{PA}$ alloy are due to the combined effect of relative density and interstitials. Nonetheless, the higher amount of oxygen and nitrogen which characterised the Ti-3Al-2.5V-PA alloy are responsible for the fact that (1) the Ti-3Al-2.5V-PA samples sintered at $1250{ }^{\circ} \mathrm{C}$ are somewhat harder than the Ti-3Al-2.5V-MA ones despite their lower relative density and (2) that the specimens processed at $1350{ }^{\circ} \mathrm{C}$ show higher hardness even though both materials have very similar relative density values. In comparison to the wrought Ti-3Al-2.5V alloy in the annealed state, whose hardness is 267 HV [29], both PM Ti-3Al-2.5V-MA and Ti-3Al-2.5V-PA alloys are characterised by higher hardness, independent of the processing parameters employed to sinter them. This is once again due to the higher amount of interstitials of the sintered materials with respect to the wrought alloy. Concerning the UTS values, PM Ti-3Al-2.5V-MA and Ti-3Al2.5V-PA alloys reach a significantly higher final strength with respect to the wrought Ti-3Al-2.5V alloy in the mill annealed state, whose 
UTS is equal to $620 \mathrm{MPa}$ [18], despite the presence of $4-5 \%$ of residual porosity. This is due to the higher amount of interstitials elements, especially oxygen percentage, of the processed PM alloy compared to the wrought alloy. It is worth mentioning that the strength achieved by the Ti-3Al-2.5V-MA and Ti-3Al-2.5V-PA alloys is similar to that of the wrought $\mathrm{Ti}-3 \mathrm{Al}-2.5 \mathrm{~V}$ subjected to a combined process of coldworking and stress-relieve (C.W.S.R., UTS $=860 \mathrm{MPa}$ ), a typical industrial process [18]. Moreover, the final UTS values shown in Fig. 7 are slightly lower but still comparable to the value specified for the wrought Ti-6Al-4V alloy (i.e. $900 \mathrm{MPa}$ [18]). Conversely to UTS, the ductility of PM Ti-3Al-2.5V-MA and Ti-3Al-2.5V-PA alloys is somewhat lower compared to the mill annealed wrought Ti-3Al-2.5V material (15\%), which is the typical behaviour of PM materials due to the residual porosity. Nevertheless, the values obtained and shown in Fig. 7 are comparable to that of the C.W.S.R. Ti-3Al-2.5V alloy (10\%) [18] or that of the wrought Ti-6Al-4V alloy (i.e. 10\% [18]). As shown in Fig. 8, the sintered titanium alloys fail through the microvoids coalescence mechanism typical of ductile metals. Quasi-static properties of the materials studied are comparable to those of the wrought material although somewhat lower dynamic properties like fatigue endurance can be expected due to the presence of the residual porosity which act as stress intensification sites. Dynamic properties could be improved by post processing the sintered alloys by means of a hot isostatic cycle which will seal the residual porosity. Finally, it is worth mentioning that the Young modulus values obtained for the Ti-3Al-2.5V-MA and Ti-3Al-2.5V-PA sintered samples are comparable to that of the wrought alloy, indicating that the amount of residual porosity present on the sintered samples (4-5\%) does not affect significantly this property. This is most probably due to the fact that starting from a level of approximately $94 \%$ of relative density, the material is in the final stage of sintering and the residual porosity is not interconnected anymore [16].

\section{Conclusions}

From this study about the factors influencing the tensile behaviour of PM Ti-3Al-2.5Valloys, it can be concluded that the fabrication of the Ti-3Al-2.5V alloy by means of uniaxial pressing and sintering is a viable alternative to the conventional metallurgical route independent of the nature of the powders used and, in particular, of the way the alloying elements are added. The level of relative density and the total amount of interstitials dissolved are the two main factors which determine the mechanical performances of PM titanium alloys. Although slight differences between the two materials were found, in general, the produced PM Ti3Al-2.5Valloys show comparable mechanical performances to those of the wrought alloy. Specifically, higher hardness and ultimate tensile strength can easily be obtained whereas care must be taken to keep high ductility. On the basis of the results shown, the materials studied are found to be potential candidates to fabricate cheaper products made out of titanium alloys.

\section{Acknowledgements}

The authors want to acknowledge the financial support from the Spanish Ministry of Science through the R\&D Projects MAT2009-14448-C02-02 and MAT2009-14547-C02-02, and from Regional Government of Madrid through the ESTRUMAT (S2009/ MAT-1585) project.

\section{References}

[1] G. Lütjering, J.C. Williams, Titanium: Engineering Materials and Processes, 1st ed., Springer, Manchester, UK, 2003.

[2] C. Leyens, M. Peters, Titanium and Titanium Alloys. Fundamentals and Applications, Wiley-VCH, Ko ln, Germany, 2003.

[3] A.M. Russell, K.L. Lee, Structure-Property Relations in Nonferrous Metals, Wiley-Interscience, New Jersey, U.S.A, 2005.

[4] R.I. Jaffee, Prog. Met. Phys. 7 (1958) 65-163.

[5] D. Henry, Materials and Coatings for Medical Devices: Cardiovascular, ASM International, Ohio, USA, 2009.

[6] M.J. Donachie (Ed.), Titanium. A Technical Guide, 2nd edition,ASM International, Ohio, USA, 2000.

[7] S.-Y. Sung, Y.-J. Kim, Mater. Sci. Eng. A 405 (2005) 173-177.

[8] F.H. Froes, D. Eylon, G.E. Eichelman, H.M. Burte, J. Met. 32 (1980) 47-54.

[9] F.H. Froes, J.E. Smugeresky, Powder Metallurgy of Titanium Alloys, The Metallurgical Society of AIME, Las Vegas, U.S.A, 1980.

[10] J.E. Smugeresky, D.B. Dawson, Powder Technol. 30 (1981) 87-94.

[11] D. Eylon, P.R. Smith, S.W. Schwenker, F.H. Froes, Status of titanium powder metallurgy, in: Webster, Young (Eds.), Industrial Applications of Titanium and Zirconium: 3rd Conference, ASTM International, Baltimore, U.S.A., 1984, pp. 48-65.

[12] F.H. Froes, D. Eylon, Titanium Powder Metallurgy - A Review, PM Aerospace Materials, Bern, Switzerland, 1984, pp. 1-19.

[13] B.E. Hurless, F.H. Froes, AMPTIAC Q. 6 (2002) 3-10.

[14] M. Mitkov, D. Božić, Mater. Charact. 37 (1996) 53-60.

[15] L. Bolzoni, P.G. Esteban, E.M. Ruiz-Navas, E. Gordo, Powder Metall. 54 (2011) $543-550$.

[16] R.M. German, Powder Metallurgy of Iron and Steel, John Wiley \& Sons, Inc., New York, 1998.

[17] L. Bolzoni, E.M. Ruiz-Navas, E. Gordo, Mater. Des. 52 (2013) 888-895.

[18] R. Boyer, G. Welsch, E.W. Collings, Materials Properties Handbook: Titanium Alloys, A. International, Ohio, USA, 1998.

[19] R.M. German, Powder Metallurgy Science, 2nd edition, MPIF - Metal Powder Industries Federation, Princeton, USA, 1994.

[20] W. Schatt, K.-P. Wieters, Powder Metallurgy. Processing and Materials, EPMA European Powder Metallurgy Association, Shrewsbury, UK, 1997.

[21] R.I. Jaffee, H.R. Ogden, D.J. Maykuth, Trans. Am. Inst. Min. Metall. Eng. 188 (1950) 1261-1266.

[22] R.I. Jaffee, I.E. Campbell, Trans. Am. Inst. Min. Metall. Eng. 185 (1949) 646-654.

[23] W.L. Finlay, J.A. Snyder, J. Met. 188 (1950) 277-286.

[24] V.A. Joshi, Titanium Alloys: An Atlas of Structures and Fracture Features, Taylor \& Francis, Boca Raton, U.S.A, 2006.

[25] S. Abkowitz, D. Rowell, J. Met. 38 (1986) 36-39.

[26] O.M. Ivasishin, V.M. Anokhin, A.N. Demidik, D.G. Savvakin, Key Eng. Mater. 188 (2000) 55-62.

[27] O.M. Ivasishin, Mater. Forum 29 (2005) 1-8.

[28] G. Friedman, R. Regn, Titanium PM Gyro Components, Metal Powders Report, 39, 1984, pp. 273-281.

[29] P.A. Russo, R.S. Seagle, Properties of titanium for industrial applications with emphasis on Ti-3Al-2.5V, in: Webster, Young (Eds.), Industrial Applications of titanium and Zirconium: 3rd Conference, ASTM International, Baltimore, U.S.A., 1984, pp. 99-112. 